\title{
Entre la autoficción poética y la poesía conversacional: Un estudio de la obra Historias Polaroid, de Luis Chaves
}

\author{
Roberto Antonio Blanco-Ramos*
}

iD https://orcid.org/0000-0001-5831-1555

\author{
Recibido: 19 de agosto, 2019 - Aceptado: 14 de noviembre, 2019
}

\section{RESUMEN}

El presente artículo ${ }^{1}$ pretende analizar la forma en que se presenta la autoficción poética en el poemario Historias Polaroid del escritor costarricense Luis Chaves. La investigación parte de la hipótesis de que la poesía conversacional despliega un escenario ideal para comprender y vislumbrar los mecanismos o recursos de la autoficción utilizados por el yo poético.

Palabras clave: Poesía, literatura autobiográfica, posmodernidad, poesía costarricense, autorepresentación.

\section{Formato de citación según APA}

Blanco-Ramos, R. (2020). Entre la autoficción poética y la poesía conversacional: Un estudio de la obra Historias Polaroid, de Luis Chaves. Revista Espiga, 19 (39), 11-26.

\section{Formato de citación según Chicago-Deusto}

Blanco-Ramos, Roberto Antonio (2020). «Entre la autoficción poética y la poesía conversacional: Un estudio de la obra Historias Polaroid, de Luis Chaves». Revista Espiga 19, n. ${ }^{\circ} 39$ (enero-junio, 2020): 11-26.

* Máster en Literatura Hispanoamericana, Universidad Complutense de Madrid, España. Bachiller en Historia de la Universidad Nacional de Costa Rica. Desde el 2016 es profesor de los cursos de historia e investigación en la Universidad Braulio Carrillo, Costa Rica. Intereses de investigación: literatura e imaginarios, literatura hispanoamericana y su vínculo con el chisme, literatura del Norte de México, narrativa de Daniel Sada, autoficción narrativa y poética. Correo: robertoblanco1890@gmail.com

1. El autor desea agradecer al Dr. Niall Binns, profesor titular de la Universidad Complutense de Madrid, por los comentarios realizados para la elaboración del presente artículo. 


\section{Introducción}

De acuerdo con los investigadores Manuel Alberca ${ }^{2}$ y Cristina Piña ${ }^{3}$, el panorama sociocultural de la posmodernidad tuvo una importante incidencia en las formas actuales o existentes de narrar, particularmente en las llamadas escrituras del yo, en las que comenzó a estructurarse un principio de ambigüedad con rasgos deconstructivistas. Para Piña, la posmodernidad planteó nuevas perspectivas en torno a las del sujeto, la racionalidad, el conocimiento, la sociedad y el arte ${ }^{4}$.

En ese sentido, la definición de posmodernidad que guía esta investigación ${ }^{5}$ se basa en el planteamiento de que esta originó una dinámica rupturista con respecto a la modernidad. Por ejemplo, Piña señala un cambio en cuanto a la idea de entender la historia como algo unitario y la de la existencia de verdades únicas ${ }^{6}$. Esto último, tal como se analizará en las siguientes secciones, resulta fundamental para entender la nueva dinámica de las escrituras del yo. Por otra parte, de acuerdo con Mijail Mondol, la categoría de posmodernidad ha sido utilizada para comprender una serie de temáticas y procedimientos literarios sobre la cultura establecida en la sociedad contemporánea ${ }^{7}$. Así, con este carácter rupturista «se anulará el principio de división que predominaba en los géneros literarios y su campo se presentará como ámbito de hibridación y experimentación $»^{8}$. Para el caso costarricense, fue durante la década de 1990 cuando la literatura se vio influenciada por rasgos posmodernos, regidos por el principio de ambigüedad que permitió el surgimiento de textos trazados por tratamientos de transgresión y experimentación ${ }^{9}$. De modo que el texto poético analizado (Historias Polaroid, de Luis Chaves) se inserta en esta tradición, bajo la óptica de la autoficción.

De esta manera, en el contexto sociocultural de la posmodernidad surge la llamada autoficción, con un claro predominio en el ámbito de la narrativa, apelando a la construcción de un texto en el cual, según Manuel Alberca: «se ofrece con plena conciencia del carácter ficticio del yo y, por tanto, aunque allí se hable de la propia existencia del autor, en principio no es prioritario ni representa una exigencia delimitar la veracidad autobiográfica ya que el texto se propone simultáneamente como ficticio y real $»^{10}$. Ahora

2. Manuel, Alberca, El pacto ambiguo: De la novela autobiográfica a la autoficción (Madrid: Biblioteca Nueva, 2007), 38-39.

3. Cristina, Piña, «La incidencia de la posmodernidad en las formas actuales de narrar», Cuadernos del CILHA (2013): 17, acceso: 15 de enero, 2020, https://dialnet.unirioja.es/servlet/articulo?codigo $=5116649$

4. Ibíd, 18

5. Para ello, la investigación se basa en los planteamientos de la autora Cristina Piña (2013), quien analiza la concepción de posmodernidad a partir de los análisis realizados por Gianni Vattimo y Frederic Jameson. Para ampliar, se pueden consultar los siguientes textos: Vattimo, Gianni. El fin de la modernidad. Barcelona: Gedisa (1987) y Jameson, Frederic. El giro cultural. Escritos seleccionados sobre el posmodernismo (1983.1998). Buenos Aires: Manantial (1999).

6. Piña, «La incidencia de...», 18.

7. Mondol López, Mijail, Identidades literarias: Una aproximación sociohistórica a la literatura costarricense (San José: EUNED, 2014), 112.

8. Piña, «La incidencia de...», 19

9. Mondol López, Identidades literarias..., 112-113.

10. Alberca, El pacto..., 33. 
bien, ¿se puede hablar de un mecanismo autoficcional en la poesía? Las investigaciones de Laura Scarano y Verónica Leucci ${ }^{11}$ han contribuido con el desarrollo de esta perspectiva. Para Scarano, los estudios sobre los vínculos existentes entre autobiografía, autoficción y poesía, son escasos y, además, el desarrollo teórico es limitado. Por esta razón, la autora ha propuesto la categoría autoficción poética con el propósito de: «llenar esa laguna y analizar las luchas y contradicciones que autobiografía y autoficción desarrollan para colonizar el enigmático espacio del poema» ${ }^{12}$.

De este modo, el presente artículo pretende analizar la forma en que se presenta la autoficción poética en el poemario indicado anteriormente, del escritor costarricense Luis Chaves (1969), publicado en el 2000 por la editorial Perro Azul. Asimismo, se parte de la hipótesis de que la poesía conversacional despliega un escenario ideal para comprender los mecanismos o recursos autoficcionales utilizados por el yo poético.

El trabajo se divide en tres apartados. En el primero se realiza un breve repaso histórico de la poesía costarricense, con el objetivo de percibir la manera en la cual la poesía conversacional se posiciona como un discurso poético contemporáneo-reciente. En el segundo, se analiza teóricamente la categoría de autoficción poética y su posible alianza con la poesía conversacional. Finalmente, en el último apartado se elabora el análisis discursivo del texto de Chaves, a partir de lo expuesto en los primeros capítulos.

\section{El camino hacia la poesía conversacional costarricense}

Este apartado procura dar cuenta de la forma en que la llamada poesía conversacional costarricense se articuló a partir de las últimas décadas del siglo XX y en la primera del XXI, como una categoría significativa, tomando en consideración que, desde la segunda mitad del XX, empiezan a surgir los primeros pasos de este discurso poético.

Los investigadores costarricenses, Carlos Cortés ${ }^{13}$ y Gustavo Solórzano ${ }^{14}$, señalan que existe un momento decisivo para ubicar el nacimiento de la poesía costarricense moderna: la publicación de la obra En el silencio de Roberto Brenes Mesén ${ }^{15}$. Así, en los

11. Para ampliar, véase los siguientes estudios: Laura Scarano, Vida en versos: autoficciones poéticas (Santa Fe: Ediciones UNL, 2014), Laura Scarano, «Poesía y nombre de autor: Entre el imaginario autobiográfico y la autoficción». Revista Celehis (2017), acceso: 15 de enero, 2020, http://humadoc.mdp.edu.ar:8080/bitstream/handle/123456789/354/Conf_Poesia_de_autor_ZARAGOZA_2015.pdf?sequence=1 y Verónica Leuci, «Autoficción, poesía y nombre propio: un debate con puertas abiertas». Revista Recial (2015) acceso: 15 de enero, 2020, https://revistas.unc.edu.ar/index.php/recial/article/view/11895

12. Laura Scarano, «Vida en verso: Historia de una pasión» (ponencia, Universidad Nacional del Litoral, Argentina, 1-3 de junio de 2013), 1 .

13. Carlos, Cortés, «La poesía costarricense de fin de siglo», Cuadernos Hispanoamericanos (1999): 37, acceso: 15 de enero, 2020, http://www.cervantesvirtual.com/obra/la-poesia-costarricense-de-fin-de-siglo-932401/

14. Gustavo Solórzano Alfaro, Retratos de una generación imposible: muestra de 10 poetas costarricenses y 21 años de su poesía (1990-2010) (San José: EUNED, 2010), 4.

15. Es importante señalar que con la figura de Brenes Mesén el modernismo ingresa de manera tardía a la literatura costarricense. De acuerdo con Mijail Mondol, este «modernismo tardío» tiene la particularidad de utilizar un lenguaje coloquial y simple. Para ampliar, véase: Mondol López, Identidades literarias..., 108-110 
primeros treinta años del siglo XX, con el impulso de Brenes Mesén, «se hace de la poesía una forma» ${ }^{16}$.

Posteriormente, en el periodo de 1930 a 1960, la influencia del vanguardismo europeo se extendió, esto coadyubó al surgimiento de importantes generaciones amparadas en las figuras del poeta Isaac Felipe Azofeifa y la poeta Eunice Odio ${ }^{17}$. Igualmente, para Cortés, en la década de 1948 a 1958, se constituyó, de forma definitiva, el vocabulario poético contemporáneo ${ }^{18}$.

A partir de 1960 se presentó un cambio esencial en cuanto al desarrollo del discurso conversacional, relacionado con la poesía de Jorge Debravo, quien sentó las bases para la paulatina conformación de una poética conversacional y de lo cotidiano. Francisco Rodríguez explica que con Debravo se puede ubicar el surgimiento de una poesía conversacional de carácter social: «La poesía conversacional de análisis social ha tenido gran trayectoria en Costa Rica, fundamentalmente por la escritura de Jorge Debravo, quien combinaba la situación enunciativa de carácter declamativo y oratórica centrada en la primera persona, con una forma de segunda persona de énfasis coloquial» ${ }^{19}$.

Desde los años setenta, la poesía costarricense atraviesa, en una clara consolidación discursiva, lo que Cortés llama un: «cruce de vías entre generaciones, tendencias y grupos poéticos, entre poetas y poéticas, diferentes y a veces muy diversas formas de entender el ejercicio poético ${ }^{20}$. Igualmente, el paulatino desarrollo de la poética conversacional, durante las tres últimas décadas del siglo XX, estuvo influenciado por la obra poética de significados autores, como Roque Dalton, Ernesto Cardenal, Otto René Castillo y la antipoesía de Nicanor Parra, enmarcada en la lógica conversacional y sujeta al contexto sociopolítico de esas décadas.

De esta forma, se establece lo que Rodríguez ha clasificado como poesía conversacional reciente-contemporánea (autores nacidos en la década de 1960) y en la que se sitúa una serie de obras publicadas en el periodo de $1989-2003^{21}$. Rodríguez plantea que el discurso conversacional al que se recurre se amplía mediante la disposición de varias poéticas en las que se logra distinguir las siguientes perspectivas: un énfasis individualista sujeto a la narratividad del mundo cotidiano, una vertiente de análisis social, un énfasis metapoético y culturista, un carácter feminista y otro que asimila las temáticas de tipo amatorio $^{22}$.

16. Cortés, «La poesía costarricense...», 37 .

17. Solórzano, Retratos de una generación..., 4 .

18. Cortés, «La poesía costarricense...», 41.

19. Francisco Rodríguez Cascante, «La poesía costarricense contemporánea y el campo discursivo conversacional», Revista Káñina, n. ${ }^{\circ} 2$ (2006): 151

20. Cortés, «La poesía costarricense...», 43.

21. Rodríguez Cascante, «La poesía costarricense contemporánea», 151-152.

22. Ibíd, 146. Rodríguez (2006) ubica a los siguientes autores y las siguientes obras dentro de esta categoríatradición: Luis Chaves: Los animales que imaginamos (1997) e Historias Polaroid (2000); María Montero: La mano suicida (2000); Jorge Arturo Mora: Se alquila esta ventana (1989); Mario Matarrita: La isla de piedra (1991) y Lluvia perpetua (2000); Carlos Manuel Villalobos: Ceremonias desde la lluvia (1995) y El primer tren que pase (2001); José María Zonta: Lobos en la brisa (1991) y Los elefantes estorban (1995); Mauricio Molina: Maremonstrum (2000); Mainor González Calvo: La sombra inconclusa (1998); Meritxell Serrano: Perfiles de tinta (1998); Elena Gutiérrez: La caja negra (2001) y Alfredo Trejos: Carta sin cuerpo (2001). 
Para concluir con este apartado, es significativo señalar que el discurso conversacional, al igual que el género autoficcional, se enriquece y profundiza con el panorama de la posmodernidad. Por ejemplo, esto sucede con los poetas señalados por Rodríguez (véase nota 21), los cuales se identifican con una serie de procesos propios de este contexto, en el sentido de lo que Frederic Jameson cataloga como una etapa postindustrial o una llamada tercera etapa tardía del capitalismo ${ }^{23}$. Esto permite entrever la formación de discursos de desencanto y desconfianza, característicos de este periodo ${ }^{24}$.

\section{Autoficción poética: una aproximación teórica}

Los análisis establecidos por Laura Scarano y Verónica Leuci parten de la importancia que posee el nombramiento del autor dentro del poema. De acuerdo con Scarano:

[...] nos centraremos en la relevancia del nombre de autor incluido en el orbe textual y su funcionamiento pragmático. Ya bien sabemos que en el nombre propio que figura en la tapa de un libro se resume de manera emblemática la existencia de lo que llamamos autor, y nos envía a una persona real que habita el mundo extratextual. Pero ¿qué pasa cuando el nombre de autor es componente de la obra misma? ¿Qué efectos de lectura desencadena cuando se «textualiza» su autor? ¿Qué juegos de lenguaje se habilitan? ¿Y qué «compromisos» con lo real implica su uso? ${ }^{25}$

Del mismo modo, Leuci considera que este nombramiento posibilita determinar la existencia del principio de ambigüedad de la autoficción poética:

El nombre propio remite, por un lado, como mencionamos, a los límites controvertidos entre autobiografía y ficción. En tanto que, por otro, la inclusión de este nombre como categoría poemática nos deriva al estatuto enunciativo del sujeto poético. Y, en relación con ambas esferas, la noción de autor o la figura de escritor se constituyen asimismo como conceptos clave, tanto por su «rol social» como por su «figura textual» ${ }^{26}$.

Además, una de las premisas fundamentales que explica y condiciona la presencia de la autoficción poética, es la definición ficcional del yo poético. Para explicar esto, Scarano recurre a la categoría de sujeto imaginario, elaborada por el investigador Jorge Montelone ${ }^{27}$ : «el sujeto imaginario se vincularía con el sujeto social [...] al tiempo que la figura autoral (para no asimilarlo con el individuo concreto del autor) introduce el contenido de la experiencia biográfica y el mundo de la vida privada $\rangle^{28}$. Por tanto, se trata de un recurso de autorepresentación discursiva que no remite en términos objetivos

23. Niall Binns «Postmodernidad en la poesía chilena contemporánea: Nicanor Parra, Jorge Teillier y Enrique Linh» (tesis de doctorado en Filología Hispánica, Universidad Complutense de Madrid, 1996), 39.

24. Rodríguez Cascante, «La poesía costarricense contemporánea», 149.

25. Laura Scarano, Vida en versos: autoficciones poéticas (Santa Fe: Ediciones UNL, 2014), 12.

26. Leuci, Verónica, «Poesía y autoficción, una alianza posible» (ponencia, VIII Congreso Internacional de Teoría y Crítica Literaria, Universidad Nacional de la Plata, 7-9 de marzo de 2012), 2, acceso: 15 de enero, 2020: http://www.memoria.fahce.unlp.edu.ar/trab_eventos/ev.2356/ev.2356.pdf

27. Para ampliar, véase: Jorge Monteleone, «Mirada e imaginario poético», en La poética de la mirada (Madrid: Visor, 2004).

28. Scarano, Vida en versos..., 33. 
al ser del yo, sino al sentir del yo poético ${ }^{29}$. De esta manera, se crea una suerte de verdad interior-metafórica. Esta verdad no debe asociarse con una certificación creíble de lo que se dice, por el contrario, debe de enlazarse con una afirmación simultánea del pasadomemoria y el impacto de la temporalidad del recuerdo que demanda el escritor y que el entendimiento ficcional reconstruye $\mathrm{e}^{30}$.

En tal sentido, la concepción de sujeto imaginario se diferencia de la estructura autobiográfica, debido a que proyecta una clara ruptura con el carácter sistematizado y organizativo del recuerdo y la memoria que pretende instaurar la autobiografía. En los siguientes ejemplos, de algunas estrofas de los poemas titulados «Variaciones sobre una misma crisis» y «Propuesta para escena de un videoclip», se puede analizar la forma en que el yo poético asimila la perspectiva del sujeto imaginario a través de la exposición del sentir y no la del ser, dejando entender como el yo poético identifica el paso del tiempo como una metáfora de «crisis», relacionándola e identificándola con su escritura, el recuerdo y el olvido:

Acabo de cumplir los 30

y ya me siento así de viejo ${ }^{31}$.

Ya pasé los 30

y todavía no tengo nada

importante que decir ${ }^{32}$.

Cada segundo nos alejamos más de personas

que creyeron saber quiénes éramos,

como si fuera así de sencillo,

como si mojarse los pies en el mar

bastara para comprender las profundidades ${ }^{33}$.

De esta forma, Laura Scarano propone, tomando como base los análisis del investigador Vincent Colonna ${ }^{34}$, que la autoficción poética «busca transmitir un universo de valores, una sensibilidad, en el marco de una relación personal percibida a la vez como auténtica y ficcional» $»^{35}$. Ese catalogado universo es asimilado a través de una estructura simbólica autobiográfica y autorreferencial, la cual se mezcla con el lenguaje poético. En palabras de Scarano: «No se trata de presentar una invención donde lo real se subsume

29. Alicia Molero de la Iglesia, «Modelos culturales y estética de la identidad», Revista Rilce, Universidad de Navarra (2012):171, En http://dadun.unav.edu/bitstream/10171/29302/1/Molero\%20de\%201a\%20Iglesia. pdf

30. Julia, Musitano, «La autoficción: una aproximación teórica: entre la retórica de la memoria y la escritura de recuerdos», Acta Literaria (2016):112, acceso: 15 de enero, 2020, https://scielo.conicyt.cl/scielo. php?script $=$ sci_issuetoc\&pid $=0717-684820160001 \& \operatorname{lng}=$ es\&nrm $=$ iso

31. Luis Chaves, Falso Documental. Poesía completa (1997-2016) (Buenos Aires: Seix Barral, 2016), 283.

32. Ibíd, 284.

33. Ibíd, 295-296.

34. Véase para ampliar: Vincent, Colonna, Autofiction \& Autres Mythomanies Littéraries (París: Tristram, 2004).

35. Scarano, Vida en versos..., 48. 
(como hacía la novela histórica, por ejemplo), sino ficcionalizar la fuente misma del lenguaje, haciendo que el yo vivido y el inventado se nivelen ${ }^{36}$.

Para Leuci, por su parte, la utilización de la autoficción dentro del contexto del género poético, destacando el marco simbólico del sujeto imaginario, representa y sugiere el entendimiento para superar la categoría de poesía autobiográfica ${ }^{37}$. Consecuentemente, según la autora, esta categoría se concibe «en el encuentro ambiguo y dinámico entre realidad y ficción», ${ }^{38} \mathrm{y}$, a su vez, «permite superar los términos de dicotomías en apariencia irreconciliables, como una alianza posible de territorios en litigio» ${ }^{39}$.

Considerando lo examinado hasta el momento, ¿De qué forma se puede enlazar el recurso poético autoficcional con el lenguaje conversacional? Este último es concebido, según Marlen Calvo, por medio de las propias experiencias subjetivas ${ }^{40}$, las cuales, en términos autoficcionales, están vinculadas al llamado sujeto imaginario. Esta subjetividad proyecta un imaginario del poeta determinado por auto imágenes y anti-imágenes ${ }^{41}$ integradas y mostradas intrínsecamente en un discurso poético autorreferencial. Conjuntamente, estas imágenes pueden desplegarse a través de la presencia constante de la reflexión o la autorreflexividad para exponer una realidad humana conflictiva y contradictoria, la cual, para el caso de la poesía de Chaves, descrita en Historias Polaroid, se asocia al vínculo familiar y la escritura.

Por ende, la discursividad de la poesía conversacional extiende un escenario con el que se identifica el yo poético (sujeto imaginario); este se enmarca en un esquema de autoreferencialidad trazado mediante perspectivas autobiográficas, asumidas dentro un marco íntimo-privado y metaliterario; de manera que, en la experiencia subjetiva que pretende revelar lo conversacional y en el que se esclarecen los mecanismos de la autoficción, se construye, siguiendo el esquema teórico propuesto por Francisco Rodríguez, mediante las siguientes características: «asume la narratividad y el versolibrismo y experimenta con el lenguaje o asume el realismo descriptivo» ${ }^{42}$. Conjuntamente, la carga testimonial que se encuentra y sustenta lo autoficcional se articula a través de proyectos colectivos y, a su vez, puede posicionarse en una perspectiva de dimensión individual.

Como se analizará en el siguiente apartado, el eje que interesa rescatar para efectuar el análisis del texto Historias Polaroid, responde al de la exposición de la dimensión individual y colectiva, mostrado a partir de una poética de la narratividad y lo descriptivo.

36. Scarano, Laura, «Poesía y nombre de autor: Entre el imaginario autobiográfico y la autoficción», Revista Celehis, (2017): 228, acceso: 15 de enero, 2020, http://humadoc.mdp.edu.ar:8080/bitstream/handle/123456789/354/Conf_Poesia_de_autor_ZARAGOZA_2015.pdf?sequence=1

37. Leuci, «Poesía y autoficción una alianza posible», 2.

38. Ibíd, 7 .

39. Ibíd.

40. Marlen Calvo Oviedo, «La poesía conversacional costarricense en la construcción de una sociedad», Revista Estudios, n. ${ }^{\circ} 22$ (2009): 181.

41. Scarano, «Poesía y nombre de autor...», 221.

42. Rodríguez Cascante, «La poesía costarricense contemporánea», 149. 


\section{«Ese territorio cercano a mi vida» ${ }^{43}$ : Autoficción y discurso conversacional en el poemario Historias Polaroid}

Si bien la referencialidad onomástica resulta vital, las propuestas teóricas examinadas en el apartado anterior sugieren la presentación de una autoficción en la que, sin aparecer este aspecto, se estructura una realidad delineada a través de un plano íntimo, construido y representado por medio de referencias autoficcionales en las que predomina la memoria individual y familiar, la exposición de su condición de escritor y la creación de una identidad literaria. En tal caso, la dinámica autoficcional que busca analizarse, tal como indica Leuci, es la siguiente: «No se trata de abocarse a la empresa detectivesca de buscar semejanzas y datos de la vida del autor esparcidos en la poesía, sino de reconocer los guiños que asoman ostensiblemente en la obra [...] proyectando una (re)creación de la figura de escritor en el plano ficcional» ${ }^{44}$.

En Historias Polaroid, existe la continua presentación de un yo poético que se identifica con el entorno familiar, en donde el recuerdo y la memoria desempeñan un rol esencial. De igual manera, en todos los poemas destaca un posicionamiento discursivo que se aleja de la «solemnidad» poética y que, en cambio, recurre a la utilización del lenguaje cotidiano, popular o coloquial. Para Camilo Retana, el poemario expone un enfoque: «desgarrado, descreído, desencantado y en riña con la literatura escrita con mayúscula» ${ }^{45}$.

En el primer poema, «Ringside», se trae a colación el recuerdo de un acontecimiento que marcó al yo poético (un combate de boxeo de Mohamed Alí que vio en la televisión) en su inicio con la vocación literaria. Este poema resulta fundamental en el sentido indicado por Leuci, ya que existe una recreación de la figura del escritor desde el inicio del poemario, el cual amplía en los otros poemas, reflejando un reconocimiento pleno de su vocación; en la segunda estrofa se expone lo siguiente:

Ese negro levantaba los guantes

y convertía el cuadrilátero

en una pista de baile.

Años después comprendí

que ese fue mi encuentro inicial con la poesía ${ }^{46}$.

Por otra parte, la comprensión autoficcional del recuerdo y la memoria se expone a partir del apego emocional dentro esquema de valores, señalado por Scarano. Este esquema distingue la asimilación de una verdad subjetiva-metafórica, delimitada dentro un espacio conversacional cotidiano y por momentos sarcástico e irónico. Este aspecto resulta significativo en la construcción del imaginario familiar descrito por el sujeto imaginario

43. La frase fue dicha por Luis Chaves en un video titulado «Algunos lugares Luis Chaves» del 2018, que aborda su trayectoria como poeta. El video puede consultarse en el siguiente enlace: https://www.youtube. $\mathrm{com} /$ watch? $=\mathrm{N} 6 \mathrm{qIS} 1 \mathrm{~K} 0$ sus

44. Verónica, Leuci, «Autoficción, poesía y nombre propio: un debate con puertas abiertas», 14.

45. Camilo Retana Alvarado, «La poesía no sirve para nada: poesía joven costarricense como discurso contrahegemónico», Revista de Lenguas Modernas, n. ${ }^{\circ} 10$ (2009): 28.

46. Ibíd, 263. 
y que engloba a la mayoría de los poemas. Asimismo, la familia forma parte de la experiencia subjetiva del lenguaje conversacional que busca y apela a la articulación poética de la dimensión individual y colectiva. Los siguientes poemas evidencian este análisis. El poema «La bajita del rincón oscuro», trazado por un tono irónico, exhibe la filiación del yo desde la añoranza maternal y el paso del tiempo; en la primera estrofa y al inicio de la segunda se lee lo siguiente:

Mamá quería que yo fuera mujer

y que no lloviera nueve meses al año

y que papá la sacara a bailar de vez en cuando.

Pero era más probable amanecer un día con tetas

o un cambio anómalo del clima,

antes que Don Luis la convidara un bolero.

Hace varios años que mi madre dejó de soñar,

hoy aguarda la vejez como un último trámite ${ }^{47}$.

Igualmente, en los poemas «C.B.P.»y «Maneras de permanecer», predomina el imaginario familiar autorreferencial, en este caso destaca el recuerdo de una muerte; en ambos poemas se evidencia la estructura autoficcional desde la intimidad, cavilando sobre el actuar de la vida y la muerte, al crear metáforas con la imagen de la sangre y el tiempo:

De niño vi a mi abuela agonizar en casa por meses.

Ahora no sé cómo era su cara, sólo recuerdo el pelo negro y largo, como si la hubiera mirado por detrás.

Cuando la sacaron los de la funeraria me acerqué a su cama vacía. Por muchos años la muerte fue para mí aquella sábana con una mancha de sangre en forma de mariposa ${ }^{48}$.

Colgado del luto de mamá escuché estas palabras que dejó caer como flores sucesivas sobre la lápida de su madre: nadie muere del todo, m'hijito.

El tiempo

le dio la razón.

El cobro del agua aún llega

47. Chaves, Falso documental..., 264.

48. Ibíd, 270 . 
a nombre de Carmen Brenes Pana,

mi abuela, muerta en el $76^{49}$.

De la misma manera, la evocación de esta imagen se construye por medio de una representación descriptiva y narrativa. Este tipo de poemas refleja la inserción de relatos y experiencias personales en las que el yo establece un reconocimiento del imaginario familiar; es decir, siguiendo el esquema propuesto por Scarano, un reflejo de cómo su discurso poético crea una identidad con el entorno autoficcional de la familia. En el poema «Bienes raíces», por ejemplo, se presenta un relato de la figura maternal:

Antes de entregar la casa

donde vivió por más de veinticuatro años,

mamá recorre en silencio

cuartos y pasillo,

la punta de los dedos

roza lentamente las paredes

Al llegar a la ventana trasera

asoma su cabeza,

como si entrara en el túnel del tiempo ${ }^{50}$.

Mientras que en el poema narrativo llamado «La dissecction d" un homme armé», se expone la historia de un personaje, en el cual, el yo reconoce la figura del abuelo paterno:

A la seis de la tarde, los días de semana, se lo veía salir de su taller de mecánica. Mojando de saliva las manos. Mismas con las que, invariablemente, los viernes golpeaba a su mujer, hijos e hijas, después de haber noqueado a dos o tres en la cantina [...]

Duro de cabeza y espíritu, sólo el licor de contrabando lograba doblegarlo en las ya citadas noches fatídicas. Cada tarde de domingo, con su pipa humeante de tabaco adquirido en el Mercado Central, dejaba su vista perderse en el cerro La Carpintera, que a esas horas era azul [...]

Ese hombre temido por enemigos, hijas, hijos y mujer es el padre de mi padre. Y con esas mismas manos, odiadas por todos los anteriores, se forjó una vida sin gloria ${ }^{51}$.

La descripción de las relaciones familiares también se muestra desde una autorreferencialidad que puede interpretarse desde el cuestionamiento de esos vínculos. Se trata de cuestionar la imagen simbólica de la representación idealizadora de la familia. De esto dan cuenta dos poemas. En «Nocault» se describe el desapego que existe entre un hijo y el padre, el título remite a una carga simbólica de lo que representa esa desunión:

Hay un mensaje de mamá

en el contestador

pide una carta para mi padre

que está por graduarse

49. Ibíd, 304.

50. Chaves, Falso documental..., 269.

51. Ibíd, 315. 
de su cursillo religioso.

Lo primero que pensé

fue en sus revistas The Ring,

en sus peleas de boxeo amateur

y en el niño que esperaba

que él lo alzara en hombros

después de ganar el título.

De eso sólo me quedan

unos viejos guantes Everlast $14 \mathrm{oz}$,

y un par de instantáneas en un álbum.

De aquello a él solo le queda

un hijo que escribe

una nota impersonal

y la envía por fax ${ }^{52}$.

Por su parte, en el poema «Video de alquiler» recalca en la indiferencia que se forja en las familias y el intento fallido de crear lazos de estabilidad:

La película terminó mal.

En el cuarto a oscuras,

hasta los créditos

irradian un sentimiento

de equivocación.

No es fácil

reunir a cuatro extraños,

y, en pocos días,

hacerlos actuar

como una familia.

Nosotros, en el intento,

llevamos toda la vida ${ }^{53}$.

Otro ejemplo de la puesta en marcha de la narratividad poética se encuentra en el siguiente extracto del poema «Las tres divinas partes (relato de autoayuda en tres entregas)», que forma parte de la segunda sección del poemario (Documentos Falsos), compuesta de poemas en prosa. A pesar de que no se hace referencia a la imagen familiar, sí se incluye el relato personal de un personaje llamado El Penca y su relación con el yo, en el marco de una disposición autoficcional:

Se llamaba Antonio pero le dicen El Penca. Fue conmigo a la primaria. Comía mocos y su sudor apestaba. Estamos hablando de dos carajillos de ocho años. Su tata era periodista, dato fácil de recordar porque nadie más en la clase tenía padre profesional [...] Luego me mudé a otra provincia y no lo vi más hasta hace un par de meses en un bar de San Pedro, donde lo encontré tomándose unos tragos con una chavala ${ }^{54}$.

\footnotetext{
52. Ibíd, 281.

53. Ibíd, 310 .

54. Chaves, Falso documental..., 321.
} 
De igual modo, en varios poemas existe una clara referencialidad a la fotografía (de ahí la alusión en el título del libro a la palabra «polaroid»). Esta remite a la funcionalidad poética del retrato, una propuesta que busca determinar el rol simbólico e identitario de su escritura en relación con la recuperación de la memoria individual y familiar. Una suerte de captar, en términos poéticos, un instante que perdure, bajo una óptica autoficcional, en la memoria y el recuerdo del yo. En «Operación o quimio», por ejemplo, destaca la última estrofa que rememora un reconocimiento del sujeto imaginario en una fotografía de su abuela:

Sigue observando al niño, mete su mano en el brassier y saca una foto de sus tres únicos nietos.

El del centro, con dientes de leche, soy $\mathrm{yo}^{55}$.

En tanto que, en «Lo que dura la felicidad», se presenta un retrato de su abuelo desde una aproximación irónica de la felicidad, destacando su efímera duración:

El abuelo de mamá, totalmente senil, dentadura de porcelana y pañales, sentado en medio de una progenie que ya no reconoce.

A la cuenta de tres todos dicen whisky.

Su sonrisa dura lo mismo que ese instante mínimo entre el flash y el obturador ${ }^{56}$.

El descubrimiento de su vocación literaria, observado en el primer poema, conlleva a que el yo asuma un reconocimiento simbólico de su posición de escritor y poeta. Por ende, esta asimilación es mostrada a partir de una clara representación metaliteraria, desde la concordancia evidente de la figura de autor-poeta, es decir, la inclusión del plano del personaje poético autoral. Por consiguiente, en varios poemas se distingue lo que Laura Scarano cataloga como metapoemas: «Estamos frente a una autorrepresentación del autor en el poema, de naturaleza ficcional (por incluirse en un texto literario), pero con efectos pragmáticos indudables» ${ }^{57}$. El poema "Arte poética I» demuestra esta orientación; en este, la figura del escritor puede remitir (véase el último verso) a lo que Scarano define como anti-imagen, en este caso de su profesión o vocación, pero que, aun así, forma parte de su identidad escritural:

La bruja me mira de soslayo, tira la muerte, el ahorcado, el loco. Pasa su mano rugosa sobre las cartas, fuma honda y exhala una sentencia,

55. Ibíd, 265.

56. Chaves, Falso documental..., 278.

57. Scarano, Vida en versos..., 43. 
un puñal de humo:

usted se equivocó de oficio ${ }^{58}$.

Una disposición similar sucede en el poema «Texto fascista»; en la segunda estrofa aparece lo siguiente:

Siglo XX d. C.

Asisto por compromiso

a una lectura de escritores

exageradamente inadvertidos

fuera del círculo familiar.

No entiendo la mitad de lo que dicen ${ }^{59}$.

Finalmente, en algunos casos, la equiparación metapoética está emparentada con la relación existente entre su condición de escritor y el ámbito familiar. Un claro ejemplo se encuentra en las siguientes estrofas del poema «Mi hermano cree que el primer nombre de Dickinson es Angie»; la primera correspondiente a la segunda, mientras que el segundo ejemplo es de la última:

Hoy, a sus veinticuatro años y aunque no lee lo que escribo, mi hermano me ayuda a vender libros. Asiste a todas mis lecturas, lo que quiere decir, máximo, dos noches al año, y como no sabe quién es ese tal Elliot, ni Vallejo, ni Dickinson, pero le gusta conversar cuando está con sus amigos, les cuenta de cuando por accidente le abrí la frente con un bate de beisbol.

Hace unos meses en un recital afirmé, con mal disimulado esnobismo que suelo imaginar animales. Mi hermano, quizás el único que escuchaba desde la última mesa, lejos de las luces, parecía decir con su mirada de desconcierto que él me prefería cuando lo sacrificábamos ${ }^{60}$.

\section{Conclusiones y reflexión final}

Este artículo ha proyectado una serie de consideraciones teóricas y literarias que incitan a continuar el debate en torno a la posibilidad de examinar la inserción de la

\footnotetext{
58. Chaves, Falso documental..., 279.

59. Chaves, Falso documental..., 293.

60. Ibíd, 266-267.
} 
autoficción en el género de la poesía en el contexto hispanoamericano y, por consiguiente, se pueden retomar en la poesía costarricense.

Para el caso de Costa Rica, por ejemplo, debe considerarse al grupo generacional que asume lo conversacional con una serie de temáticas que trazan perspectivas de carácter autobiográfico, con un significativo énfasis en la narratividad y en lo metapoético; y, en algunos casos, asumiendo principios de transgresión literaria.

Asimismo, resulta importante determinar cómo desde la década de 1990, cuando la literatura costarricense asume rasgos literarios relacionados con la posmodernidad, la poesía recupera los elementos analizados en esta investigación. Así, por ejemplo, uno de los ejes que puede retomarse es el análisis autoficcional poético de los distintos discursos de desencanto y desconfianza sobre la sociedad contemporánea posmoderna, en donde la llamada escritura del yo asume un rol protagónico.

Con el propósito de dilucidar la presencia de recursos autoficcionales, se planteó que la discursividad perfilada en la poesía conversacional resulta fundamental dentro de un esquema de autorepresentación simbólica. Este sirvió de base para determinar la construcción del principio de ambigüedad del sujeto imaginario, el cual rige las pautas de la autoficción. Por ende, el principal mecanismo que pudo observarse fue la implementación de la narratividad, debido a que exhibe y comunica un marco de sentimientos y experiencias con los que el llamado sujeto imaginario se identifica. Este proceso permitió determinar, como lo explica Verónica Leucci, el reconocimiento de características que reconstruyen una figura visiblemente apegada a su formación literaria.

Asimismo, a pesar de que en los poemas analizados no existe una referencia visible del nombre del autor-escritor, se estableció que la autoficción poética del texto está configurada mediante la representación autobiográfica (verdad subjetiva-metafórica) que expone dos aspectos esenciales: una clara referencialidad a su oficio de escritor y, por otra parte, exhibe un contenido emocional-afectivo y valorativo, implicado en algunas experiencias del pasado familiar.

\title{
ABSTRACT
}

Between poetic autofiction and conversational poetry: A study of Historias Polaroid by Luis Chaves

\begin{abstract}
This article aims to analyze the way in which poetic autofiction is presented in the poetry collection Historias Polaroid by Costa Rican writer Luis Chaves. The research hypothesis is that conversational poetry presents the ideal scenario to understand and perceive the autofiction mechanisms or resources used by the poetic I.
\end{abstract}

Key words: Poetry, autobiographical literature, postmodernity, Costa Rican poetry, self-representation. 


\section{RÉSUMÉ}

\section{Entre l'autofiction poétique et la poésie conversationnelle: Une étude de l'œuvre Historias Polaroid de Luis Chaves}

Cet article vise à analyser l'autofiction poétique dans le recueil de poèmes Historias Polaroid (Histoires Polaroid) de l'écrivain costaricien Luis Chaves. La recherche part de l'hypothèse que la poésie conversationnelle constitue un scénario idéal pour comprendre et entrevoir les mécanismes ou les ressources de l'autofiction utilisés par le je lyrique.

Mots clés: Poésie, littérature autobiographique, postmodernité, poésie costaricienne, autoreprésentation.

\section{Referencias bibliográficas}

Alberca, Manuel. El pacto ambiguo: De la novela autobiográfica a la autoficción. Madrid: Biblioteca Nueva, 2007.

Binns, Niall. «Postmodernidad en la poesía chilena contemporánea: Nicanor Parra, Jorge Teillier y Enrique Linh». Tesis de doctorado Filología Hispánica, Universidad Complutense de Madrid, 1996.

Chaves, Luis. Falso Documental. Poesía completa (1997-2016). Buenos Aires: Seix Barral, 2016.

Colonna, Vincente, Autofiction \& Autres Mythomanies Littéraries. París: Tristram, 2004.

Cortés, Carlos. «La poesía costarricense de fin de siglo», Cuadernos Hispanoamericanos (1999): 37-44. Acceso: 15 de enero, 2020. http://www.cervantesvirtual.com/obra/la-poesia-costarricense-de-fin-de-siglo-932401/

Leuci, Verónica. «Autoficción, poesía y nombre propio: un debate con puertas abiertas». Revista Recial (2015):1-17. Acceso: 15 de enero, 2020. https://revistas.unc.edu.ar/index.php/recial/article/view/11895.

Leuci, Verónica. «Poesía y autoficción una alianza posible». Ponencia, VIII Congreso Internacional de Teoría y Crítica Literaria, Universidad Nacional de la Plata, 7-9 de marzo de 2012. Acceso: 15 de enero, 2020. http://www.memoria.fahce.unlp.edu.ar/trab_eventos/ev.2356/ev.2356.pdf.

Molero de la Iglesia, Alicia. «Modelos culturales y estética de la identidad», Revista Rilce, Universidad de Navarra (2012): 168-184. Acceso: 15 de enero, 2020. http://dadun.unav.edu/bitstream/10171/29302/1/Molero $\% 20 \mathrm{de} \% 201 \mathrm{a} \% 20$ Iglesia.pdf

Monteleone, Jorge. «Mirada e imaginario poético». En: La poética de la mirada. Madrid: Visor, 2004.

Mondol, López Mijail. Identidades literarias: Una aproximación sociohistórica a la literatura costarricense. San José: EUNED, 2014.

Musitano, Julia. «La autoficción: una aproximación teórica: entre la retórica de la memoria y la escritura de recuerdos», Acta Literaria (2016): 103-123. Acceso: 15 de enero, 2020. https://scielo.conicyt.cl/scielo. php?script $=$ sci_issuetoc\&pid $=0717-684820160001 \& \operatorname{lng}=\mathrm{es} \& \mathrm{nrm}=\mathrm{iso}$

Calvo Oviedo, Marlen. «La poesía conversacional costarricense en la construcción de una sociedad», Revista Estudios, n. ${ }^{\circ} 22$ (2009): 179-188.

Piña, Cristina. «La incidencia de la posmodernidad en las formas actuales de narrar», Cuadernos del CILHA (2013): 16-37. Acceso: 15 de enero, 2020. https://dialnet.unirioja.es/servlet/articulo?codigo=5116649

Retana Alvarado, Camilo. «La poesía no sirve para nada: poesía joven costarricense como discurso contrahegemónico». Revista de Lenguas Modernas, n. ${ }^{\circ} 10$ (2009): 27-35. 
Rodríguez Cascante, Francisco. «La poesía costarricense contemporánea y el campo discursivo conversacional», Revista Káñina, n. ${ }^{\circ} 2$ (2006):145-161.

Scarano, Laura. Vida en versos: autoficciones poéticas. Santa Fe: Ediciones UNL, 2014.

Scarano, Laura. «Poesía y nombre de autor: Entre el imaginario autobiográfico y la autoficción». Revista Celehis (2017): 219-239. Acceso: 15 de enero, 2020. http://humadoc.mdp.edu.ar:8080/bitstream/handle/123456789/354/Conf_Poesia_de_autor_ZARAGOZA_2015.pdf?sequence=1

Scarano, Laura. «Vida en verso: Historia de una pasión». Ponencia realizada en la Universidad Nacional del Litoral, Argentina, 1-3 de junio de 2013.

Solórzano Alfaro, Gustavo. Retratos de una generación imposible: muestra de 10 poetas costarricenses y 21 años de su poesía (1990-2010). San José: EUNED, 2010. 